\title{
New fixed point theorems for $\theta-\phi$ contraction in complete metric spaces
}

\author{
Dingwei Zheng ${ }^{\mathrm{a}}$, Zhangyong Cai ${ }^{\mathrm{b}}$, Pei Wang ${ }^{\mathrm{c}, *}$ \\ ${ }^{a}$ College of Mathematics and Information Science, Guangxi University, Nanning, Guangxi 530004, P. R. China. \\ ${ }^{b}$ Department of Mathematics, Guangxi Teachers Education University, Nanning, Guangxi 530023, P. R. China. \\ ${ }^{c}$ School of Mathematics and Information Science, Yulin Normal University, Yulin, Guangxi 537000, P. R. China. \\ Communicated by B. Samet
}

\begin{abstract}
In this paper, we introduce the notions of $\theta-\phi$ contraction and $\theta-\phi$ Suzuki contraction and establish some new fixed point theorems for these mappings in the setting of complete metric spaces. The results presented in the paper improve and extend the corresponding results due to Banach, Browder [F. E. Browder, Nederl. Akad. Wetensch. Proc. Ser. A Indag. Math., 30 (1968), 27-35], Suzuiki [T. Suzuki, Nonlinear Anal., 71 (2009), 5313-5317], Kannan [R. Kannan, Amer. Math. Monthly, 76 (1969), 405-408], Jleli and Samet [M. Jleli, B. Samet, J. Inequal. Appl., 2014 (2014), 8 pages]. Finally, we give an example to illustrate them. (C)2017 All rights reserved.
\end{abstract}

Keywords: Fixed point, complete metric space, $\theta-\phi$ contraction.

2010 MSC: 47H10, 54H25.

\section{Introduction and preliminaries}

As is well-known, Banach contraction principle is one of the famous results in fixed point theory.

Banach contraction principle: Let $(X, d)$ be a complete metric space, and $T: X \rightarrow X$ be a self-mapping. If there exists a constant $k \in[0,1)$ such that

$$
d(T x, T y) \leqslant k d(x, y)
$$

then $T$ has a unique fixed point in $X$.

Later, a lot of authors have generalized it, modifying the inequality $d(T x, T y) \leqslant k d(x, y)$ by introducing corresponding functional inequality. For example, Wardowski [12] introduced the contractive condition by $\tau+F(d(T x, T y)) \leqslant F(d(x, y))$. Jleli and Samet [6] introduced the contractive condition by $\theta(d(T x, T y)) \leqslant$ $[\theta(d(x, y))]^{k}$ (e.g., see $[1,3,8-10,12]$ and the references therein for others).

In 2014, Jleli and Samet [6] introduced a new type of contractions called $\theta$-contraction.

\footnotetext{
*Corresponding author

Email addresses: dwzheng@gxu.edu.cn (Dingwei Zheng), zycaigxu2002@126.com (Zhangyong Cai), 274958670@qq.com (Pei Wang)
}

doi:10.22436/jnsa.010.05.32 
Definition 1.1 ([6]). Let $(X, d)$ be a metric space. A mapping $T: X \rightarrow X$ is said to be an $\theta$-contraction if there exist $\theta \in \Theta$ and $k \in(0,1)$ such that for any $x, y \in X$,

$$
d(T x, T y) \neq 0 \Rightarrow \theta(d(T x, T y)) \leqslant[\theta(d(x, y))]^{k},
$$

where $\theta:(0, \infty) \rightarrow(1, \infty)$ satisfies the following conditions:

$\left(\Theta_{1}\right) \theta$ is non-decreasing;

$\left(\Theta_{2}\right)$ for each sequence $\left\{t_{n}\right\} \subset(0, \infty), \lim _{n \rightarrow \infty} \theta\left(t_{n}\right)=1$ if and only if $\lim _{n \rightarrow \infty} t_{n}=0^{+}$;

$\left(\Theta_{3}\right) \theta$ is continuous on $(0, \infty)$;

$\left(\Theta_{4}\right)$ there exist $r \in(0,1)$ and $l \in(0, \infty]$ such that $\lim _{t \rightarrow 0^{+}} \frac{\theta(t)-1}{t^{r}}=l$.

From Definition 1.1, we can know that the Banach contraction is a particular case of $\theta$-contractions, meanwhile there exists a $\theta$-contraction which is not a Banach contraction (see [6]). By using the notion of $\theta$-contraction, Jleli and Samet [6] proved a fixed point theorem which is a generalization of the Banach contraction principle as the following:

Theorem $1.2([6])$. Let $(\mathrm{X}, \mathrm{d})$ be a complete metric space and $\mathrm{T}: \mathrm{X} \rightarrow \mathrm{X}$ be a $\theta$-contraction. Then $\mathrm{T}$ has a unique fixed point $\mathrm{X}^{*} \in \mathrm{X}$ such that the sequence $\left\{\mathrm{T}^{\mathrm{n}} \mathrm{x}\right\}$ converges to $\mathrm{X}^{*}$ for every $\mathrm{x} \in \mathrm{X}$.

The condition $\left(\Theta_{4}\right)$ is so strong that there exist a lot of functions which satisfy the conditions $\left(\Theta_{1}\right)$, $\left(\Theta_{2}\right)$, and $\left(\Theta_{3}\right)$ but they do not satisfy the condition $\left(\Theta_{4}\right)$.

In this paper, we denote by $\Theta$ the set of functions satisfying the conditions $\left(\Theta_{1}\right),\left(\Theta_{2}\right)$, and $\left(\Theta_{3}\right)$.

The purpose of this paper is to prove some fixed point theorems for $\theta-\phi$ contraction and $\theta-\phi$ Suzuki contraction in the setting of complete metric spaces. The results presented in the paper improve and extend the corresponding results of Banach, Suzuki [11], Jleli and Samet [6], Kannan [7], Browder [3], Dugundji-Granas [4], Boyd-Wong [2], and Matkowski [8]. Finally, we give an example to illustrate them.

\section{Main results}

Denote by $\Phi$ the set of functions $\phi:[1, \infty) \rightarrow[1, \infty)$ satisfying the following conditions:

$\left(\Phi_{1}\right) \phi:[1, \infty) \rightarrow[1, \infty)$ is non-decreasing;

$\left(\Phi_{2}\right)$ for each $t>1, \lim _{n \rightarrow \infty} \phi^{n}(t)=1$;

$\left(\Phi_{3}\right) \phi$ is continuous on $[1, \infty)$.

Lemma 2.1. If $\phi \in \Phi$, then $\phi(1)=1$ and $\phi(t)<\mathrm{t}$ for each $\mathrm{t}>1$.

Proof. Suppose, on the contrary, that there exists $t_{0}>1$ such that $\phi\left(t_{0}\right) \geqslant t_{0}$. The monotonicity of $\phi(t)$ yields $\phi^{n}\left(t_{0}\right) \geqslant t_{0}$ for each $n \in N$, which is a contradiction to $\lim _{n \rightarrow \infty} \phi^{n}\left(t_{0}\right)=1$. Thus $\phi(t)<t$ for each $t>1$. Since $1 \leqslant \phi(1) \leqslant \phi(t)<t$ for each $t>1$, passing to limit as $t \rightarrow 1$, we have $\phi(1)=1$.

Based on the function $\phi \in \Phi$, we give the following definition.

Definition 2.2. Let $(X, d)$ be a metric space and $T: X \rightarrow X$ be a mapping.

(1) $\mathrm{T}$ is said to be a $\theta-\phi$ contraction if there exist $\theta \in \Theta$ and $\phi \in \Phi$ such that for any $x, y \in X$,

$$
d(T x, T y) \neq 0 \Rightarrow \theta(d(T x, T y)) \leqslant \phi[\theta(N(x, y))]
$$

(2) $T$ is said to be a $\theta-\phi$ Suzuki contraction if there exist $\theta \in \Theta$ and $\phi \in \Phi$ such that for any $x, y \in X, T x \neq$ Ty,

$$
\frac{1}{2} d(x, T x)<d(x, y) \Rightarrow \theta(d(T x, T y)) \leqslant \phi[\theta(N(x, y))]
$$

where

$$
N(x, y)=\max \{d(x, y), d(x, T x), d(y, T y)\}
$$


(3) $T$ is said to be a $\theta-\phi$ Kannan-type contraction if there exist $\theta \in \Theta$ and $\phi \in \Phi$ such that for any $x, y \in X, T x \neq T y$,

$$
\theta(d(T x, T y)) \leqslant \phi\left[\theta\left(\frac{d(x, T x)+d(y, T y)}{2}\right)\right] .
$$

We can easily see that $\theta-\phi$ contractions and $\theta-\phi$ Kannan-type contractions are $\theta-\phi$ Suzuki contractions.

Theorem 2.3. Suppose $(X, d)$ is a complete metric space and suppose $\mathrm{T}: \mathrm{X} \rightarrow \mathrm{X}$ is a $\theta-\phi$ Suzuki contraction, i.e, there exist $\theta \in \Theta$ and $\phi \in \Phi$ such that for any $x, y \in X, T x \neq T y$,

$$
\frac{1}{2} d(x, T x)<d(x, y) \Rightarrow \theta(d(T x, T y)) \leqslant \phi[\theta(N(x, y))]
$$

where

$$
N(x, y)=\max \{d(x, y), d(x, T x), d(y, T y)\} .
$$

Then $T$ has a unique fixed point $x^{*} \in X$ such that the sequence $\left\{T^{n} x\right\}$ converges to $x^{*}$ for every $x \in X$.

Proof. Suppose $x_{0} \in X$ is an arbitrary point. Define a sequence $\left\{x_{n}\right\}$ in $X$ by $x_{n+1}=T x_{n}$ for each $n \in N$.

Case 1. If $x_{n+1}=x_{n}$ for some $n \in N$, then $x^{*}=x_{n}$ is a fixed point for $T$.

Case 2. If $x_{n+1} \neq x_{n}$ for each $n \in N$, then $d\left(x_{n+1}, x_{n}\right)>0$ for all $n \in N$. Hence, for $n \in N$

$$
\frac{1}{2} d\left(x_{n}, T x_{n}\right)<d\left(x_{n}, T x_{n}\right) .
$$

Making use of the inequality (2.1) with $x=x_{n}$ and $y=T x_{n}$, we get

$$
\theta\left(d\left(T x_{n}, T x_{n+1}\right)\right) \leqslant \phi\left[\theta\left(N\left(x_{n}, x_{n+1}\right)\right)\right]
$$

where

$$
N\left(x_{n}, x_{n+1}\right)=\max \left\{d\left(x_{n}, x_{n+1}\right), d\left(x_{n}, T x_{n}\right), d\left(x_{n+1}, T x_{n+1}\right)\right\}=\max \left\{d\left(x_{n}, x_{n+1}\right), d\left(x_{n+1}, x_{n+2}\right)\right\} .
$$

If $N\left(x_{n}, x_{n+1}\right)=d\left(x_{n+1}, x_{n+2}\right)$, then it follows from (2.2) that

$$
\theta\left(d\left(x_{n+1}, x_{n+2}\right)\right)=\theta\left(d\left(T x_{n}, T x_{n+1}\right)\right) \leqslant \phi\left[\theta\left(d\left(x_{n+1}, x_{n+2}\right)\right)\right]
$$

which is a contradiction by Lemma 2.1. So equality (2.3) implies $N\left(x_{n}, x_{n+1}\right)=d\left(x_{n}, x_{n+1}\right)$. By (2.2), we have

$$
\theta\left(d\left(T x_{n}, T x_{n+1}\right)\right) \leqslant \phi\left[\theta\left(d\left(x_{n}, x_{n+1}\right)\right)\right] .
$$

Repeating this step, we conclude that

$$
\theta\left(d\left(T x_{n-1}, T x_{n}\right)\right) \leqslant \phi\left[\theta\left(d\left(x_{n-1}, x_{n}\right)\right)\right] \leqslant \phi^{2}\left[\theta\left(d\left(x_{n-2}, x_{n-1}\right)\right)\right] \leqslant \cdots \leqslant \phi^{n}\left[\theta\left(d\left(x_{0}, x_{1}\right)\right)\right] .
$$

By the definition of $\theta$ and property $\left(\Phi_{2}\right)$, we have

$$
\lim _{n \rightarrow \infty} \phi^{n}\left[\theta\left(d\left(x_{0}, x_{1}\right)\right)\right]=1 .
$$

And by $\left(\Theta_{2}\right)$,

$$
\lim _{n \rightarrow \infty} d\left(x_{n}, x_{n+1}\right)=0 .
$$

Next, we prove that $\left\{x_{n}\right\}$ is a Cauchy sequence in $X$. Otherwise, there exist $\eta>0$ and sequences $\{p(n)\}$ and $\{q(n)\}$ such that for all $n \in N$,

$$
n<q(n)<p(n), d\left(x_{p(n)}, x_{q(n)}\right) \geqslant \eta \text {, and } d\left(x_{p(n)-1}, x_{q(n)}\right)<\eta .
$$


Then,

$$
\eta \leqslant d\left(x_{p(n)}, x_{q(n)}\right) \leqslant d\left(x_{p(n)}, x_{p(n)-1}\right)+d\left(x_{p(n)-1}, x_{q(n)}\right) \leqslant \eta+d\left(x_{p(n)}, x_{p(n)-1}\right) .
$$

It follows from (2.4) and the above inequality,

$$
\lim _{n \rightarrow \infty} d\left(x_{p(n)}, x_{q(n)}\right)=\eta
$$

By triangle inequality of $d$, we have

$$
\left|d\left(x_{p(n)+1}, x_{q(n)+1}\right)-d\left(x_{p(n)}, x_{q(n)}\right)\right| \leqslant d\left(x_{p(n)}, x_{p(n)+1}\right)+d\left(x_{q(n)}, x_{q(n)+1}\right) .
$$

From (2.4), (2.5), and the above inequality,

$$
\lim _{n \rightarrow \infty} d\left(x_{p(n)+1}, x_{q(n)+1}\right)=\eta .
$$

By (2.1) with $x=x_{p(n)}, y=x_{q(n)}$, we get

$$
\theta\left(d\left(x_{p(n)+1}, x_{q(n)+1}\right)\right) \leqslant \phi\left[\theta\left(\max \left\{d\left(x_{p(n)}, x_{q(n)}\right), d\left(x_{p(n)}, x_{p(n)+1}\right), d\left(x_{q(n)}, x_{q(n)+1}\right)\right\}\right)\right] .
$$

Using (2.4), (2.5), (2.6), $\left(\Theta_{3}\right)$, and $\left(\Phi_{3}\right)$, passing to limit as $n \rightarrow \infty$, we obtain

$$
\theta(\eta) \leqslant \phi[\theta(\eta)]
$$

It follows from Lemma 2.1 that

$$
\theta(\eta) \leqslant \phi[\theta(\eta)]<\theta(\eta)
$$

which is a contradiction. Thus $\left\{x_{n}\right\}$ is a Cauchy sequence in $X$.

Since $X$ is complete, then $\left\{x_{n}\right\}$ converges to some point $X^{*}$ in $X$.

Fix $p \in N$, we claim that

$$
\frac{1}{2} \mathrm{~d}\left(x_{\mathfrak{p}}, T x_{p}\right)<\mathrm{d}\left(x_{p}, x^{*}\right), \quad \text { or } \frac{1}{2} \mathrm{~d}\left(T x_{p}, T^{2} x_{p}\right)<\mathrm{d}\left(T x_{p}, x^{*}\right) .
$$

Otherwise,

$$
\frac{1}{2} d\left(x_{p}, T x_{p}\right) \geqslant d\left(x_{p}, x^{*}\right) \text { and } \frac{1}{2} d\left(T x_{p}, T^{2} x_{p}\right) \geqslant d\left(T x_{p}, x^{*}\right)
$$

Therefore,

$$
2 d\left(x_{p}, x^{*}\right) \leqslant d\left(x_{p}, T x_{p}\right) \leqslant d\left(x_{p}, x^{*}\right)+d\left(x^{*}, T x_{p}\right),
$$

which implies that

$$
d\left(x_{p}, x^{*}\right) \leqslant d\left(x^{*}, T x_{p}\right)
$$

It follows from (2.7) and (2.8) that

$$
d\left(x_{p}, x^{*}\right) \leqslant d\left(x^{*}, T x_{p}\right) \leqslant \frac{1}{2} d\left(T x_{p}, T^{2} x_{p}\right) .
$$

Since $\frac{1}{2} d\left(x_{p}, T x_{p}\right) \leqslant d\left(x_{p}, T x_{p}\right)$, using (2.1) with $x=x_{p}(n), y=T x_{p}(n)$, we have

$$
\theta\left(d\left(T x_{p}, T^{2} x_{p}\right)\right) \leqslant \phi\left[\theta\left(\max \left\{d\left(x_{p}, T x_{p}\right), d\left(T x_{p}, T^{2} x_{p}\right)\right\}\right)\right] .
$$

By Lemma 2.1 and from the definitions of $\phi$ and $\theta$, we obtain

$$
d\left(T x_{p}, T^{2} x_{p}\right)<d\left(x_{p}, T x_{p}\right) .
$$

It follows from (2.7), (2.9), and (2.10) that

$$
d\left(T x_{p}, T^{2} x_{p}\right)<d\left(x_{p}, T x_{p}\right) \leqslant d\left(x_{p}, x^{*}\right)+d\left(x^{*}, T x_{p}\right) \leqslant \frac{1}{2} d\left(T x_{p}, T^{2} x_{p}\right)+\frac{1}{2} d\left(T x_{p}, T^{2} x_{p}\right)=d\left(T x_{p}, T^{2} x_{p}\right),
$$

which is a contradiction. That is to say, for each $n \in N$,

$$
\frac{1}{2} d\left(x_{n}, T x_{n}\right)<d\left(x_{n}, x^{*}\right), \text { or } \frac{1}{2} d\left(T x_{n}, T^{2} x_{n}\right)<d\left(T x_{n}, x^{*}\right)
$$


Case 1. If there exists a subsequence $\left\{n_{k}\right\}$ such that for each $k \in N$,

$$
\frac{1}{2} d\left(x_{n_{k}}, T x_{n_{k}}\right)<d\left(x_{n_{k}}, x^{*}\right),
$$

then

$$
\theta\left(d\left(T x_{n_{k}}, T x^{*}\right)\right) \leqslant \phi\left[\theta\left(d\left(x_{n_{k}}, x^{*}\right)\right)\right] .
$$

By Lemma 2.1 and from the definitions of $\phi$ and $\theta$, we have

$$
\lim _{k \rightarrow \infty} d\left(T x_{n_{k}}, T x^{*}\right)=0
$$

Therefore,

$$
d\left(x^{*}, T x^{*}\right)=\lim _{k \rightarrow \infty} d\left(x_{n_{k}+1}, T x^{*}\right)=\lim _{k \rightarrow \infty} d\left(T x_{n_{k}}, T x^{*}\right)=0 .
$$

Case 2. If there exists a subsequence $\left\{n_{k}\right\}$ such that for each $k \in N$,

$$
\frac{1}{2} d\left(T x_{n_{k}}, T^{2} x_{n_{k}}\right)<d\left(T x_{n_{k}}, x^{*}\right)
$$

then

$$
\theta\left(d\left(T^{2} x_{n_{k}}, T x^{*}\right)\right) \leqslant \phi\left[\theta\left(d\left(T x_{n_{k}}, x^{*}\right)\right)\right] .
$$

By Lemma 2.1 and from the definitions of $\phi$ and $\theta$, we have

$$
\lim _{k \rightarrow \infty} d\left(T^{2} x_{n_{k}}, T x^{*}\right)=0 .
$$

Therefore,

$$
d\left(x^{*}, T x^{*}\right)=\lim _{k \rightarrow \infty} d\left(x_{n_{k}+2}, T x^{*}\right)=\lim _{k \rightarrow \infty} d\left(T^{2} x_{n_{k}}, T x^{*}\right)=0 .
$$

Thus, $x^{*}$ is a fixed point of $T$.

Now, we shall show that $T$ has at most one fixed point. Suppose there exists another fixed point $\mathrm{y}^{*}$ of $\mathrm{T}$ such that $\mathrm{T} x^{*}=x^{*} \neq \mathrm{T} y^{*}=y^{*}$. Then,

$$
d\left(T x^{*}, T y^{*}\right)=d\left(x^{*}, y^{*}\right)>0, \text { and } 0=\frac{1}{2} d\left(x^{*}, T x^{*}\right)<d\left(x^{*}, y^{*}\right) .
$$

By (2.1) and Lemma 2.1,

$$
\theta\left(d\left(x^{*}, y^{*}\right)\right)=\theta\left(d\left(T x^{*}, T y^{*}\right)\right) \leqslant \phi\left[\theta\left(d\left(x^{*}, y^{*}\right)\right)\right]<\theta\left(d\left(x^{*}, y^{*}\right)\right),
$$

a contradiction.

Remark 2.4. Theorem 2.3 improves the main results in Suzuki [11].

It follows from Definition 1.1 and Theorem 2.3, we obtain the following fixed point theorems for $\theta-\phi$ contraction and $\theta-\phi$ Kannan-type contraction.

Theorem 2.5. Let $(\mathrm{X}, \mathrm{d})$ be a complete metric space and $\mathrm{T}: \mathrm{X} \rightarrow \mathrm{X}$ be a $\theta-\phi$ contraction, then $\mathrm{T}$ has a unique fixed point $x^{*} \in X$ such that the sequence $\left\{T^{n} x\right\}$ converges to $x^{*}$ for every $x \in X$.

Remark 2.6. Theorem 2.5 improves the Banach contraction principle, the corresponding results of Browder [3], Dugundji-Granas [4], Boyd-Wong [2], Matkowski [8] and some recent results in Jleli and Samet [6].

Theorem 2.7. Let $(\mathrm{X}, \mathrm{d})$ be a complete metric space and $\mathrm{T}: \mathrm{X} \rightarrow \mathrm{X}$ be a $\theta-\phi$ Kannan-type contraction, then $\mathrm{T}$ has a unique fixed point $\mathrm{X}^{*} \in \mathrm{X}$ such that the sequence $\left\{\mathrm{T}^{\mathrm{n}} \mathrm{x}\right\}$ converges to $\mathrm{x}^{*}$ for every $\mathrm{x} \in \mathrm{X}$.

Remark 2.8. Theorem 2.7 improves the main results in Kannan [7]. 
The following corollary is Kannan's theorem [7].

Corollary 2.9. Let $(\mathrm{X}, \mathrm{d})$ be a complete metric space and $\mathrm{T}: \mathrm{X} \rightarrow \mathrm{X}$ be a Kannan type mapping, that is, if there exists $\alpha \in\left[0, \frac{1}{2}\right)$ such that for all $x, y \in X$,

$$
d(T x, T y) \leqslant \alpha(d(x, T x)+d(y, T y))
$$

then $\mathrm{T}$ has a unique fixed point $\mathrm{x}^{*} \in \mathrm{X}$ and for every $\mathrm{x} \in \mathrm{X}$ the sequence $\left\{\mathrm{T}^{\mathrm{n}} \mathrm{x}\right\}$ converges to $\mathrm{x}^{*}$.

Proof. If $\alpha=0$, it is easy to prove. So we suppose $\alpha \in\left(0, \frac{1}{2}\right)$. Let

$$
\theta(t)=e^{t}
$$

for all $\mathrm{t} \in[0,+\infty)$, and

$$
\phi(t)=t^{2 \alpha}
$$

for all $t \in[1,+\infty)$. It is obvious that $\theta \in \Theta, \phi \in \Phi$. In what follows, we prove that $T$ is a $\theta-\phi$ Kannan-type contraction.

$$
\begin{aligned}
\theta(d(T x, T y))=e^{d(T x, T y)} \leqslant e^{\alpha(d(x, T x)+d(y, T y))} & =e^{2 \alpha\left(\frac{d(x, T x)+d(y, T y)}{2}\right)} \\
& =\left(e^{\left(\frac{d(x, T x)+d(y, T y)}{2}\right)}\right)^{2 \alpha} \\
& =\left(\theta\left(\frac{d(x, T x)+d(y, T y)}{2}\right)\right)^{2 \alpha}=\phi\left[\theta\left(\frac{d(x, T x)+d(y, T y)}{2}\right)\right] .
\end{aligned}
$$

Therefore, from Theorem 2.7, $T$ has a unique fixed point $x^{*} \in X$ and for every $x \in X$ the sequence $\left\{T^{n} x\right\}$ converges to $x^{*}$.

The following corollary is Browder's theorem [3].

Corollary 2.10. Let $(X, d)$ be a complete metric space and $\mathrm{T}: \mathrm{X} \rightarrow \mathrm{X}$ be a mapping such that for all $\mathrm{x}, \mathrm{y} \in \mathrm{X}$,

$$
d(T x, T y) \leqslant \varphi(d(x, y))
$$

where $\varphi: \mathrm{R}_{+} \rightarrow \mathrm{R}_{+}$be an increasing and right continuous function such that $\varphi(\mathrm{t})<\mathrm{t}$ for $\mathrm{t}>0$. Then $\mathrm{T}$ has a unique fixed point $x^{*} \in X$ and for every $x \in X$ the sequence $\left\{T^{n} x\right\}$ converges to $x^{*}$.

Proof. We can suppose that $\varphi$ is a strictly increasing and continuous function due to Theorem 1 of [5]. Let

$$
\theta(t)=e^{t}
$$

for all $t \in[0,+\infty)$, and

$$
\phi(t)=e^{\varphi(\ln t)}
$$

for all $t \in[1,+\infty)$. Obviously, $\theta \in \Theta, \phi \in \Phi$.

By the definition of $\phi$, we have $\phi\left(e^{t}\right)=e^{\varphi(t)}$. In what follows, we prove that $T$ is a $\theta-\phi$ contraction.

$$
\theta(d(T x, T y))=e^{d(T x, T y)} \leqslant e^{\varphi(d(x, y))}=\phi\left[e^{d(x, y)}\right]=\phi[\theta(d(x, y))] .
$$

Therefore, from Theorem 2.5, $T$ has a unique fixed point $x^{*} \in X$ and for every $x \in X$ the sequence $\left\{T^{n} x\right\}$ converges to $x^{*}$.

Due to Theorem 1 of [5], the results of Browder [3], Dugundji-Granas [4], Boyd-Wong [2], and Matkowski [8] are equivalent. Therefore, our results presented in the paper improve and extend the corresponding results of them by Corollary 2.10. 


\section{Example}

In this section, we give an example to illustrate our results.

Example 3.1. Let $X=\{0, \pm 1, \pm 2, \ldots\}$ endowed with the standard metric $d(x, y)=|x-y|$ for all $x, y \in X$. Define the mapping $\mathrm{T}: \mathrm{X} \rightarrow \mathrm{X}$ by

$$
T x= \begin{cases}0, & \text { if } x=0 \\ -(n-1), & \text { if } x=n \\ n-1, & \text { if } x=-n\end{cases}
$$

At first, we observe that the Banach contraction principle cannot be applied since for all $n>m>2$, we have

$$
d(T n, T m)=n-m=d(n, m) .
$$

And Browder's result cannot be applied too. Secondly, $\mathrm{T}$ is not a Kannan-type map. In fact, let there exist $\alpha \in\left[0, \frac{1}{2}\right)$ such that

$$
d(T x, T y) \leqslant \alpha d(x, T x)+\alpha d(y, T y)
$$

for all $x, y \in X$, and let $x=n, y=0$. By the above inequality we know that

$$
n-1=d(T n, T 0) \leqslant \alpha d(n, T n)+\alpha d(0, T 0)=\alpha(2 n-1)
$$

for all $n \in N$. That is $\alpha \geqslant \frac{n-1}{2 n-1}$. Passing to limit, we obtain $\alpha \geqslant \frac{1}{2}$, which yields a contradiction. So $T$ is not a Kannan-type map.

Now, let the function $\theta:(0, \infty) \rightarrow(1, \infty)$ defined by

$$
\theta(\mathrm{t})=5^{\mathrm{t}}
$$

And define $\phi:[1, \infty) \rightarrow[1, \infty)$ by

$$
\phi(t)= \begin{cases}1, & \text { if } 1 \leqslant t \leqslant 2 \\ t-1, & \text { if } t \geqslant 2\end{cases}
$$

Obviously, $\theta \in \Theta, \phi \in \Phi$.

In what follows, we prove that $T$ is a $\theta-\phi$ Kannan-type contraction. We consider four three cases.

Case 1. $x=n \geqslant 1, y=0$ or $x=-n(n \geqslant 1), y=0$. In this case, we have

$$
\begin{aligned}
d(T x, T y) & =n-1, \\
d(x, T x) & =2 n-1, \\
d(y, T y) & =0, \\
\theta(d(T x, T y)) & =\theta(n-1)=5^{n-1}, \\
\phi\left(\theta\left(\frac{d(x, T x)+d(y, T y)}{2}\right)\right) & =\phi\left(\theta\left(\frac{d(x, T x)}{2}\right)\right) \\
& =\phi\left(\theta\left(\frac{2 n-1}{2}\right)\right) \\
& =\phi\left(5^{n-\frac{1}{2}}\right) \\
& =5^{n-\frac{1}{2}}-1 \\
& =5^{n-1+\frac{1}{2}}-1 \\
& =\sqrt{5} \times 5^{n-1}-1 \geqslant 5^{n-1} \\
& =\theta(d(T x, T y)) .
\end{aligned}
$$


Case 2. $x=n>y=m \geqslant 1$ or $x=-n<y=-m \leqslant-1$. In this case, we have

$$
\begin{aligned}
d(T x, T y) & =n-m, \\
d(x, T x) & =2 n-1, \\
d(y, T y) & =2 m-1, \\
\phi\left(\theta\left(\frac{d(x, T x)+d(y, T y)}{2}\right)\right) & =\phi\left(\theta\left(\frac{2 n+2 m-2}{2}\right)\right) \\
& =\phi(\theta(n+m-1)) \\
& =\phi\left(5^{n+m-1}\right) \\
& =5^{2 m-1} \times 5^{n-m}-1 \\
& \geqslant 5^{n-m}=\theta(d(T x, T y)) .
\end{aligned}
$$

Case 3. $x=n, y=-m, n>m \geqslant 1$. In this case, we have

$$
\begin{aligned}
d(T x, T y) & =n+m-2, \\
d(x, T x) & =2 n-1, \\
d(y, T y) & =2 m-1, \\
\phi\left(\theta\left(\frac{d(x, T x)+d(y, T y)}{2}\right)\right) & =\phi\left(\theta\left(\frac{2 n+2 m-2}{2}\right)\right) \\
& =\phi(\theta(n+m-1)) \\
& =\phi\left(5^{n+m-1}\right) \\
& =5 \times 5^{n+m-2}-1 \\
& \geqslant 5^{n+m-2}=\theta(d(T x, T y)) .
\end{aligned}
$$

Therefore, we have for all $x, y \in X$

$$
\theta(d(T x, T y)) \leqslant \phi\left[\theta\left(\frac{d(x, T x)+d(y, T y)}{2}\right)\right] .
$$

Thus, $\mathrm{T}$ is a $\theta-\phi$ Kannan-type contraction. So all the hypotheses of Theorem 2.7 are satisfied, thus $\mathrm{T}$ has a fixed point. In this example $x=0$ is the fixed point.

\section{Acknowledgment}

The authors are grateful to the referee for useful suggestions and comments. This research is supported by National Natural Science Foundation of China (Nos. 11461002, 11461003) and Guangxi Natural Science Foundation (2016GXNSFAA380003, 2016GXNSFAA380317).

\section{References}

[1] F. Bojor, Fixed point theorems for Reich type contractions on metric spaces with a graph, Nonlinear Anal., 75 (2012), 3895-3901. 1

[2] D. W. Boyd, J. S. W. Wong, On nonlinear contractions, Proc. Amer. Math. Soc., 20 (1969), 458-464. 1, 2.6, 2

[3] F. E. Browder, On the convergence of successive approximations for nonlinear functional equations, Nederl. Akad. Wetensch. Proc. Ser. A Indag. Math., 30 (1968), 27-35. 1, 1, 2.6, 2, 2

[4] J. Dugundji, A. Granas, Weakly contractive maps and elementary domain invariance theorem, Bull. Soc. Math. Gréce (N.S.), 19 (1978), 141-151. 1, 2.6, 2

[5] J. R. Jachymski, Equivalence of some contractivity properties over metrical structures, Proc. Amer. Math. Soc., 125 (1997), 2327-2335. 2

[6] M. Jleli, B. Samet, A new generalization of the Banach contraction principle, J. Inequal. Appl., 2014 (2014), 8 pages. 1, $1.1,1,1.2,1,2.6$ 
[7] R. Kannan, Some results on fixed points, II, Amer. Math. Monthly, 76 (1969), 405-408. 1, $2.8,2$

[8] J. Matkowski, Integrable solutions of functional equations, Dissertationes Math. (Rozprawy Mat.), 127 (1975), 68 pages. 1, 1, 2.6, 2

[9] H. Piri, P. Kumam, Some fixed point theorems concerning F-contraction in complete metric spaces, Fixed Point Theory Appl., 2014 (2014), 11 pages.

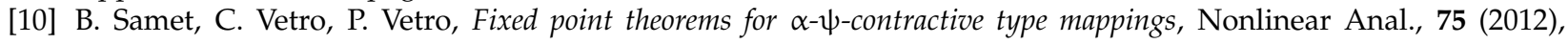
2154-2165. 1

[11] T. Suzuki, A new type of fixed point theorem in metric spaces, Nonlinear Anal., 71 (2009), 5313-5317. 1, 2.4

[12] D. Wardowski, Fixed points of a new type of contractive mappings in complete metric spaces, Fixed Point Theory Appl., 2012 (2012), 6 pages. 1 